\title{
Regulation by Adrenal Corticosteroids of Sodium and Potassium Transport in Loop of Henle and Distal Tubule of Rat Kidney
}

\author{
Bruce A. Stanton \\ Department of Physiology, Dartmouth Medical School, Hanover, New Hampshire 03756
}

\begin{abstract}
Studies were conducted to examine the effects of adrenalectomy (ADX) and selective, physiological adrenal corticosteroid replacement on sodium and potassium transport by the superficial loop of Henle and distal tubule of rat kidney in vivo. In the loop of Henle, ADX inhibited sodium reabsorption by 33\%. Whereas dexamethasone had no effect on reabsorption, aldosterone increased sodium transport to control levels. Thus, physiological levels of mineralocorticoids, but not glucocorticoids, control a fraction of sodium reabsorption in the loop of Henle. ADX also inhibited potassium reabsorption in the loop of Henle. Both dexamethasone and aldosterone reversed the inhibition, although only aldosterone increased reabsorption to control levels. In the distal tubule, ADX reduced sodium reabsorption by $44 \%$. Both aldosterone and dexamethasone stimulated reabsorption: however, only aldosterone increased transport to control. Potassium secretion by the distal tubule was also reduced $34 \%$ by ADX. Aldosterone, but not dexamethasone, stimulated secretion. Thus, physiological levels of aldosterone regulate a fraction of sodium reabsorption and potassium secretion in the distal tubule.
\end{abstract}

\section{Introduction}

Adrenal corticosteroid hormones play an important role in the regulation of salt and water excretion by the kidneys. Addisonian patients and animals deficient in these hormones have a decreased ability to generate a maximally concentrated urine (13). Sodium reabsorption by the loop of Henle is decreased in adrenalectomized rats, which suggests that part of the defect in the ability to concentrate the urine results from a reduction in the single effect of the countercurrent multiplier in the thick ascending limb of Henle's loop (4-8). In addition, some but not all studies have shown that adrenalectomy reduces potassium reabsorption in the loop of Henle $(6,9,10)$. Attempts to assess the effects of selective mineralocorticoid and glucocorticoid replacement on sodium and potassium reabsorption by the loop of Henle in adrenalectomized animals have yielded contradictory results (4-8).

One important factor bearing on this controversy is the use by some investigators of inappropriately high doses of aldosterone and glucocorticoids, which results in nonspecific binding of the hormone to both classes of adrenal corticosteroid receptors (11). A second difficulty in interpreting many studies is the occurrence,

Portions of this work have been published in abstract form (1986. Kidney Int. 29:407). 1986.

Received for publication 15 May 1986 and in revised form 8 August

J. Clin. Invest.

(c) The American Society for Clinical Investigation, Inc.

$0021-9738 / 86 / 12 / 1612 / 09 \$ \$ 1.00$

Volume 78, December 1986, 1612-1620 after adrenalectomy and hormone administration, of changes in glomerular filtration rate and the delivery of sodium and water to the loop of Henle, factors known to have important influences on sodium reabsorption by the loop (12-21). For example, since glucocorticoids enhance glomerular filtration rate and increase salt and water delivery to the loop of Henle, it is difficult, by free-flow micropuncture techniques, to separate a direct effect of glucocorticoids from these indirect stimulatory factors.

Adrenal corticosteroids also regulate sodium reabsorption and potassium secretion by the distal tubule $(6,19,21-24)$. However, the long-term effects of physiological levels of these hormones on the distal tubule have not been examined.

The present study was conducted to overcome the above shortcomings by administering physiological doses of the hormones and by controlling tubule fluid flow rate and composition through microperfusion of single tubules, in situ.

\section{Methods}

\section{Experimental protocol}

Experiments were conducted on male Sprague-Dawley rats (Charles River Breeding Laboratories, Inc., Boston, MA.) ranging in weight from 240 to $254 \mathrm{~g}$. Animals were anesthetized with Nembutal $(35 \mathrm{mg} / \mathrm{kg}$ body wt i.p.) and were either sham-adrenalectomized or adrenalectomized $10 \mathrm{~d}$ before study. At the time of adrenalectomy an Alzet osmotic minipump (2002, Alza Corp., Palo Alto, CA) was implanted in the neck of each animal to permit infusion of either vehicle, aldosterone, or dexamethasone for $10 \mathrm{~d}$ as described below.

Group 1: control. Sham-control that received vehicle (polyethylene glycol 400, J. T. Baker Chemical Co., Phillipsburg, NJ) as described previously (20).

Group 2: $A D X .^{1}$ adrenalectomized animals that received vehicle only.

Group 3: $D E X$. adrenalectomized animals that received dexamethasone $(1.2 \mu \mathrm{g} / 100 \mathrm{~g}$ body $\mathrm{wt})$.

Group 4: $A L D O$. adrenalectomized animals that received aldosterone $(0.5 \mu \mathrm{g} / 100 \mathrm{~g}$ body $\mathrm{wt})$.

We have shown previously that the dose of dexamethasone used was the lowest that increased glomerular filtration rate and plasma levels of insulin and glucose in adrenalectomized rats to values measured in shamadrenalectomized animals (20). Furthermore, rats given this dose exhibited normal weight gain (see Results). The replacement dose of aldosterone was chosen because it resembled the daily secretory rate in rats and resulted in plasma levels of aldosterone similar to those measured in awake, unstressed rats on the same dietary intake (20).

After surgery and minipump implantation, all animals were pair-fed (Prolab 3000 rat diet; Agway, Inc., Trenton, NJ, potassium content $1.5 \%$ and sodium content $0.58 \%$ ); sham-controls were given distilled water to drink ad lib. whereas the animals in the other three groups were given a solution containing $0.9 \%$ sodium chloride and $1.2 \%$ dextrose ad lib.

On the day of study, rats were anesthetized with inactin (Byk Gluden,

1. Abbreviations used in this paper: ADX, adrenalectomized animals that received vehicle only; ALDO, adrenalectomized animals that received aldosterone $(0.5 \mu \mathrm{g} / 100 \mathrm{~g}$ body $\mathrm{wt})$; DEX, adrenalectomized animals that received dexamethasone $(1.2 \mu \mathrm{g} / 100 \mathrm{~g}$ body $\mathrm{wt})$. 
Konstanz, Federal Republic of Germany), $100 \mathrm{mg} / \mathrm{kg}$ body wt i.p., and prepared for micropuncture as described previously (24). The right carotid artery was catheterized to allow for blood pressure monitoring and periodic blood sampling for measurement of sodium and potassium. The left jugular vein was cannulated to allow for fluid administration. Immediately after insertion of the venous catheter, all rats were given a 2ml bolus of a Ringer's solution $\left(\mathrm{NaCl}, 115 \mathrm{mM}, \mathrm{NaHCO}_{3} 25 \mathrm{mM} ; \mathrm{KCl}\right.$, $4 \mathrm{mM} ; \mathrm{MgCl}_{2}, 1 \mathrm{mM} ; \mathrm{CaCl}_{2}, 1 \mathrm{mM} ; \mathrm{Na}_{2} \mathrm{HPO}_{4}, 1.62 \mathrm{mM}$; and $\mathrm{NaH}_{2} \mathrm{PO}_{4}$, $0.38 \mathrm{mM}$ ) followed by a continuous infusion of this fluid at a rate of 4.7 $\mathrm{ml} / \mathrm{h}$. In adrenalectomized animals with no hormone replacement (group 2), polyvinylpyrolidine (3\%) was added to the Ringer's solution to maintain glomerular filtration rate and renal blood flow near normal values $(20,25)$.

Continuous microperfusion of superficial loops of Henle, ${ }^{2}$ in situ, was performed to measure sodium, potassium, and water transport under conditions of constant flow rate and sodium delivery. This technique has been described in detail previously (16-18) and involved pumpdriven microperfusion from the late proximal tubule to an early distal tubule of the same nephron. Briefly, a perfusion pipette was placed in the last surface loop of the proximal tubule and a castor oil block was placed upstream of the perfusion pipette. A vent was made upstream of the castor oil block to allow glomerular filtration in that nephron to continue. A pipette filled with stained (Sudan Black) heavy mineral oil was inserted into the early distal segment and was used to collect fluid during a timed interval. The perfusion pipette contained a solution similar in composition to that normally found in the late proximal tubule $(\mathrm{NaCl}$, $125 \mathrm{mM}$; $\mathrm{NaHCO}_{3}, 15 \mathrm{mM} ; \mathrm{KCl}, 4 \mathrm{mM} ; \mathrm{MgCl}_{2}, 1 \mathrm{mM} ; \mathrm{Na}_{2} \mathrm{HPO}_{4}$, $1.62 \mathrm{mM}$; and $\mathrm{NaH}_{2} \mathrm{PO}_{4}, 0.38 \mathrm{mM}$ ). In addition, $0.1 \%$ Hercules green dye $\# 2$ and $100 \mu \mathrm{Ci} / \mathrm{ml}$ [methoxy ${ }^{3} \mathrm{H}$ ]inulin were added to the perfusion solution. The perfusion solution sodium concentration was $143.2 \mathrm{mM}$; potassium $4.0 \mathrm{mM}$; osmolality $278 \mathrm{mosmol} / \mathrm{kg}$, and $\mathrm{pH} 7.0\left(5 \% \mathrm{CO}_{2}\right)$. The [methoxy- ${ }^{3} \mathrm{H}$ ] inulin was dialyzed as described by Schafer et al. (26). The perfusion rate achieved in vivo was calculated from the rate of fluid flow in the early distal tubule, multiplied by the ratio of inulin concentrations in collected/perfusion fluids.

In a second series of experiments, designed to examine the effects of adrenalectomy and hormone replacement on sodium and potassium transport by the superficial distal tubule, loops of Henle were perfused as described above; then, fluid was collected first from the late distal tubule and next from the early distal tubule in the same nephron.

At the end of each experiment, silicone rubber (Canton Biomedical Products, Boulder, $\mathrm{CO}$ ) was injected into the distal tubule of each nephron studied. After the renal tissue was digested in $25 \% \mathrm{NaOH}$ the rubber casts were dissected and the puncture sites were identified. Table I summarizes the results of these dissections. There were no differences in the site of collection, in either the early or late distal tubule, among the groups. Furthermore, the distance between collection sites was similar in all groups.

At the conclusion of each experiment, a sample of arterial blood was taken for the determination of plasma sodium and potassium concentration.

\section{Morphometric analysis of loops of Henle}

The ultrastructure of the cells in the thick ascending limb of Henle's loop was examined by morphometric and electron microscopic techniques. A second series of rats was used for this purpose and it included sham-control and adrenalectomized animals given vehicle, aldosterone, or dexamethasone for $10 \mathrm{~d}$ as for the first series. Methods of anesthesia

2. The loop of Henle refers to the nephron segment between the last surface convolution of the proximal tubule and the early distal collection site. The perfused segments include some of the $S_{2}$ and $S_{3}$ segments of the proximal tubule, the thin descending and thick ascending limb of the loop of Henle, the macula densa, and part of the distal convoluted tubule. The superficial distal tubule is also a heterogeneous epithelium and is composed of the distal convoluted tubule, connecting tubule, and initial collecting tubule (27).
Table I. Summary of Localization of Puncture Sites in Distal Tubule

\begin{tabular}{lllr}
\hline & ED & LD & \multicolumn{1}{l}{ L } \\
\hline & & & $m m$ \\
Control $(n=15)$ & $28.5 \%$ & $75.0 \%$ & 2.34 \\
& \pm 3.0 & \pm 4.2 & \pm 0.10 \\
ADX $(n=13)$ & $26.0 \%$ & $64.0 \%$ & 2.30 \\
& \pm 2.5 & \pm 3.0 & \pm 0.17 \\
DEX $(n=7)$ & $21.3 \%$ & $71.5 \%$ & 2.20 \\
& \pm 1.0 & \pm 6.7 & \pm 0.10 \\
ALDO $(n=24)$ & $29.0 \%$ & $77.2 \%$ & 2.03 \\
& \pm 1.8 & \pm 7.5 & \pm 0.10 \\
Statistical comparisons & NS & NS & NS \\
\hline
\end{tabular}

Percent of distance between macula densa and confluence with a second distal tubule. ED, early distal; LD, late distal; $L$, length of distal tubule. Number of tubules in parentheses. NS, no significant differences among the four experimental groups. Data represent mean \pm SE.

and the procedure for fixation of the kidneys and processing the tissue for electron microscopic observation have been described in detail (27). In one series of experiments, designed to examine the cortical region of the thick ascending limb, kidneys were perfused with a modified Karnovsky's solution (27), which adequately preserves the cells in the cortex. Because of the increase in tissue osmolality in the outer medulla, $0.4 \mathrm{M}$ sodium chloride was added to the fixative solution when cells from the inner and outer stripe of the outer medulla were examined (28). Fixation was considered as acceptable when the tubule lumina were patent and the cytological architecture was comparable with previous studies in the rat, and a normal appearance of mitochondria and nuclei was observed (29).

5-7 thick ascending limbs from each region of the kidney (cortex and outer and inner stripes of the outer medulla) were photographed with a Zeiss $10 \mathrm{~B}$ electron microscope and enlarged during printing to a final magnification of 10,000 times. To eliminate any possible observer bias, all sections were coded. The results from each animal represent a single observation. The following parameters were measured in each tubule by methods described in detail previously (27): (a) surface density, which is the area of cell membrane to cell volume $\left(\mathrm{S}_{\mathrm{V}}\right) ;(b)$ boundary length, which is the length of membrane (B); $(c)$ tubule area (A); and $(d)$ volume density of mitochondria, which is the ratio of the volumes of mitochondria/cell, times 100 .

\section{Analytical methods}

Sodium and potassium concentrations in plasma were determined by flame photometry (model 443; Instrumentation Laboratory, Inc., Lexington, MA) and in tubule fluid samples by helium glow spectrophotometry (American Instrument Co., Silver Spring, MD). $\left[{ }^{3} \mathrm{H}\right]$ Inulin radioactivity was measured by liquid scintillation counting.

\section{Calculations}

In microperfusion studies, net sodium and potassium transport rates by loops of Henle were calculated from the amount of each ion delivered by the perfusion pipette minus the amount collected by the collection pipette. For the distal tubule, net transport was calculated as the difference in the rate of delivery between the early and late tubule collection sites. Net water flux was the difference between the perfusion rate (see above) and collection rate. Net fluxes are positive for reabsorption and negative for secretion. Results for ion and water transport rates from tubules in each group of animals were pooled to obtain the mean values reported ( $n$, number of tubules).

Statistical analysis involved a preliminary analysis of the data using a one-way analysis of variance. If there was a significant difference $(P$ 


\begin{tabular}{|c|c|c|c|c|c|}
\hline & Weight & $\Delta$ Weight & $\mathbf{P}_{\mathrm{Na}_{\mathrm{a}}}$ & $\mathbf{P}_{\mathbf{K}}$ & Blood pressure \\
\hline & $g$ & $g$ & $m M$ & $m M$ & $m m H g$ \\
\hline Control $(n=9)$ & $245 \pm 15$ & $+56 \pm 12$ & $145.4 \pm 1.6$ & $4.4 \pm 0.1$ & $123 \pm 4$ \\
\hline $\operatorname{ADX}(n=10)$ & $254 \pm 5$ & $+48 \pm 7$ & $142.4 \pm 2.2$ & $5.8 \pm 0.3$ & $113 \pm 4$ \\
\hline $\operatorname{DEX}(n=7)$ & $240 \pm 8$ & $+49 \pm 6$ & $142.3 \pm 1.4$ & $6.0 \pm 0.4$ & $139 \pm 5$ \\
\hline $\operatorname{ALDO}(n=12)$ & $250 \pm 7$ & $+51 \pm 5$ & $145.9 \pm 0.9$ & $4.8 \pm 0.2$ & $119 \pm 4$ \\
\hline \multicolumn{6}{|l|}{ Statistical comparisons } \\
\hline Control vs. ADX & NS & NS & NS & $P<0.01$ & NS \\
\hline ADX vs. DEX & NS & NS & NS & NS & $P<0.01$ \\
\hline ADX vs. ALDO & NS & NS & NS & $P<0.01$ & NS \\
\hline DEX vs. control & NS & NS & NS & $P<0.01$ & $P<0.01$ \\
\hline ALDO vs. control & NS & NS & NS & NS & NS \\
\hline
\end{tabular}

$\Delta$ Weight, change in body weight during hormone administration; $P_{N a}$, plasma sodium concentration; $P_{K}$, plasma potassium concentration. Number of animals in parentheses. Data represent mean \pm SE.

$<0.05$ ) among means, the least significant test was used to evaluate the statistical significance between particular mean values $(20,27)$. All data are expressed as mean $\pm \mathrm{SE}$.

\section{Results}

Systemic parameters. Table II summarizes some systemic data on the four groups of animals studied. Both the body weight at the time of study and weight gain during the $10 \mathrm{~d}$ after surgery were similar among the groups. Although plasma sodium concentration was unchanged, plasma potassium concentration was significantly higher in ADX and DEX than in controls and ALDO-treated groups. Mean arterial blood pressure was higher in the DEX group compared with the other three groups.

In a previous study we measured blood acid-base status and studied renal function in a group of similarly treated animals (20). In that study only small differences in the acid-base status of the animals were noted. Specifically, plasma bicarbonate was $3 \mathrm{mM}$ lower $(P<0.05)$ in the ADX and DEX animals than in the other two groups. Arterial $\mathrm{pH}$ and $\mathrm{PCO}_{2}$ were not statistically different. Glomerular filtration rate and urinary potassium excretion were similar in all groups during intravenous infusion of Ringer's solution. On the other hand, sodium excretion was increased in ADX and DEX compared with controls and ALDO groups.

Transport data: loop of Henle. Tables III-V summarize the data for water, sodium, and potassium transport by the loop of Henle. The tubule perfusion rate and the percent recovery of inulin were similar in all groups of animals (Table III). In contrast, the collection rate of fluid, the ratios of inulin in collected tubule fluid/perfusion fluid, and fluid reabsorption among the groups were significantly different. ADX significantly decreased fluid reabsorption. Whereas DEX did not produce a detectable increase in water reabsorption, ALDO significantly increased water reabsorption in ADX rats. However, ALDO did not restore reabsorption to control levels (Table III).

Data on sodium reabsorption in the loop of Henle are summarized in Table IV and Fig. 1. Net sodium reabsorption was reduced $33 \%$ by adrenalectomy from $1,977 \pm 67 \mathrm{pmol} / \mathrm{min}$ to $1,492 \pm 75 \mathrm{pmol} / \mathrm{min}$. Whereas dexamethasone given to adrenalectomized rats did not significantly effect sodium reabsorption, aldosterone stimulated net transport to a value similar to that measured in controls. Table IV reveals that these alterations in transport were in part the result of a decrease in the ability

Table III. Water Reabsorption: Loop of Henle

\begin{tabular}{|c|c|c|c|c|c|}
\hline & Perfusion rate & Collection rate & Inulin recovery & $\mathrm{TF} / \mathrm{PF}$ inulin & $\mathbf{J}_{\mathbf{v}}$ \\
\hline & $n l / \min$ & $n l / m i n$ & $\%$ & & $n l / m i n$ \\
\hline Control $(n=15)$ & $20.5 \pm 0.5$ & $13.2 \pm 0.7$ & $98.2 \pm 2.0$ & $1.60 \pm 0.06$ & $7.3 \pm 0.5$ \\
\hline $\operatorname{ADX}(n=17)$ & $19.0 \pm 0.5$ & $15.0 \pm 0.3$ & $97.4 \pm 1.9$ & $1.28 \pm 0.03$ & $4.0 \pm 0.5$ \\
\hline $\operatorname{DEX}(n=17)$ & $19.2 \pm 0.3$ & $13.8 \pm 0.5$ & $96.3 \pm 1.8$ & $1.41 \pm 0.04$ & $5.1 \pm 0.4$ \\
\hline $\operatorname{ALDO}(n=24)$ & $19.8 \pm 0.4$ & $14.0 \pm 0.4$ & $99.2 \pm 1.7$ & $1.45 \pm 0.04$ & $5.9 \pm 0.5$ \\
\hline \multicolumn{6}{|l|}{ Statistical comparisons } \\
\hline Control vs. ADX & NS & $P<0.05$ & NS & $P<0.01$ & $P<0.01$ \\
\hline ADX vs. DEX & NS & NS & NS & NS & NS \\
\hline ADX vs. ALDO & NS & NS & NS & $P<0.05$ & $P<0.01$ \\
\hline DEX vs. control & NS & NS & NS & $P<0.05$ & $P<0.01$ \\
\hline ALDO vs. control & NS & NS & NS & $P<0.05$ & $P<0.05$ \\
\hline
\end{tabular}

$\mathrm{TF} / \mathrm{PF}$ inulin is the ratio of inulin concentration in tubule fluid collected at the early distal site/perfusion fluid; $\mathbf{J}_{\mathbf{v}}$, water reabsorption. Number of tubules in parentheses. Data represent mean \pm SE. 
Table IV. Sodium Reabsorption: Loop of Henle

\begin{tabular}{lllll}
\hline & {$[\mathrm{Na}]_{\mathrm{ED}}$} & $\mathrm{TF} / \mathrm{PF}[\mathrm{Na}]_{\mathrm{ED}}$ & $\mathrm{J}_{\mathrm{N}}$ & FR $_{\mathrm{Na}}$ \\
\hline & $m M$ & & $p m o l / m i n$ & $\%$ \\
Control $(n=15)$ & $75.9 \pm 3.1$ & $0.52 \pm 0.02$ & $1,977 \pm 67$ & $66.3 \pm 2.5$ \\
ADX $(n=17)$ & $86.4 \pm 3.7$ & $0.58 \pm 0.03$ & $1,492 \pm 75$ & $52.8 \pm 2.3$ \\
DEX $(n=17)$ & $84.9 \pm 2.4$ & $0.59 \pm 0.02$ & $1,599 \pm 44$ & $57.8 \pm 1.7$ \\
ALDO $(n=24)$ & $78.1 \pm 3.5$ & $0.53 \pm 0.02$ & $1,839 \pm 70$ & $62.5 \pm 2.2$ \\
Statistical & & & & \\
$\quad$ comparisons & & & & \\
Control vs. ADX & $P<0.05$ & $P<0.05$ & $P<0.01$ & $P<0.01$ \\
ADX vs. DEX & NS & NS & NS & NS \\
ADX vs. ALDO & $P<0.05$ & $P<0.05$ & $P<0.01$ & $P<0.01$ \\
DEX vs. control & $P<0.05$ & $P<0.05$ & $P<0.01$ & $P<0.05$ \\
ALDO vs. & & & & NS \\
\multicolumn{1}{c}{ control } & NS & NS & NS & NS \\
\hline
\end{tabular}

$[\mathrm{Na}]_{\mathrm{ED}}$, concentration of sodium in early distal tubule; TF/PF[Na $]_{\mathrm{ED}}$, ratio of sodium concentration in tubule fluid at early distal site/perfusion fluid; $\mathbf{J}_{\mathrm{Na}}, a b-$ solute reabsorption of sodium; $\mathbf{F R}_{\mathbf{N a}}$, fractional reabsorption of sodium entering loop of Henle. Number of tubules in parentheses. Data represent mean \pm SE.

of the thick ascending limb to reabsorb sodium. Inasmuch as sodium reabsorption in the thick ascending limb reduces sodium concentration in tubule fluid entering the early distal tubule, due to the low osmotic water permeability of the thick ascending limb, a change in tubule fluid sodium concentration indicates an alteration in sodium reabsorption in the thick limb. In control experiments, sodium concentration in the early distal tubule was $75.9 \pm 3.1 \mathrm{mM}$, and it increased to $86.4 \pm 3.7 \mathrm{mM}$ in ADX animals $(P<0.05)$ and to $84.9 \pm 2.4 \mathrm{mM}(P<0.05)$ in DEXtreated animals. With aldosterone treatment sodium concentration was $78.1 \pm 3.5 \mathrm{mM}$, a value that was similar to control and significantly lower than the values in ADX and DEX $(P<0.05)$.

Data on potassium transport in the loop of Henle are summarized in Table $\mathrm{V}$ and Fig. 2. Potassium reabsorption was inhibited by adrenalectomy from $36.2 \pm 3.3 \mathrm{pmol} / \mathrm{min}$ in control to $1.8 \pm 3.5 \mathrm{pmol} / \mathrm{min}$ in $\operatorname{ADX}(P<0.01)$. The last value was not significantly different from zero; in fact, in 8 of 17 tubules, in ADX rats, potassium was secreted. Although dexamethasone significantly increased potassium reabsorption compared with ADX, from $1.8 \pm 3.5 \mathrm{pmol} / \mathrm{min}$ in ADX to $21.4 \pm 3.8 \mathrm{pmol} / \mathrm{min}$ in DEX $(P<0.01)$, the latter value remained significantly less than that in control and ALDO.

These alterations in potassium reabsorption were primarily the result of changes in the potassium concentration of tubule fluid. In control, potassium concentration in the early distal tubule was $3.5 \pm 0.2 \mathrm{mM}$, and it increased to $4.7 \pm 0.4 \mathrm{mM}$ in ADX $(P<0.01)$. Both dexamethasone and aldosterone significantly decreased tubule fluid potassium concentration in adrenalectomized animals to $4.0 \pm 0.3$ and $3.0 \pm 0.2 \mathrm{mM}$, respectively $(P$ $<0.05)$. Potassium concentrations in ALDO and DEX animals were not statistically different from one another.

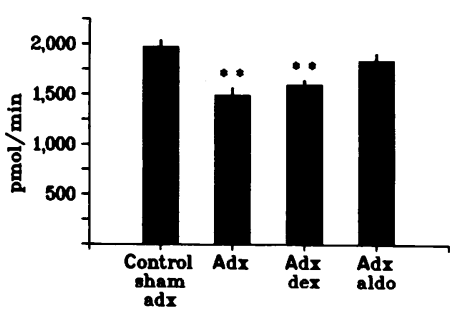

Figure 1. Sodium reabsorption: loop of Henle. ${ }^{* *} P$ $<0.01$ vs. control-sham and ADX-ALDO. Data represent mean \pm SE.
Table V. Potassium Reabsorption: Loop of Henle

\begin{tabular}{lllcc}
\hline & {$[\mathrm{K}]_{\mathrm{ED}}$} & $\mathrm{TF} / \mathrm{PF}[\mathrm{K}]_{\mathrm{ED}}$ & $\mathrm{J}_{\mathrm{K}}$ & $\mathrm{FR}_{\mathbf{K}}$ \\
\hline & $n M$ & & $p m o l / \mathrm{min}$ & $\%$ \\
& & & & \\
Control $(n=15)$ & $3.5 \pm 0.2$ & $0.87 \pm 0.06$ & $36.2 \pm 3.3$ & $44.5 \pm 4.2$ \\
ADX $(n=17)$ & $4.7 \pm 0.4^{*}$ & $1.15 \pm 0.11^{*}$ & $1.8 \pm 3.5 \ddagger$ & $3.4 \pm 0.5 \ddagger$ \\
$\operatorname{DEX}(n=17)$ & $4.0 \pm 0.3$ & $1.00 \pm 0.06$ & $21.4 \pm 3.8 \ddagger$ & $28.4 \pm 5.2 \ddagger$ \\
$\operatorname{ALDO}(n=24)$ & $3.0 \pm 0.2$ & $0.75 \pm 0.05$ & $37.6 \pm 2.5$ & $47.2 \pm 3.2$ \\
& & & & \\
\hline
\end{tabular}

$[\mathrm{K}]_{\mathrm{ED}}$, concentration of potassium in early distal tubule; $\mathrm{TF} / \mathrm{PF}[\mathrm{K}]_{\mathrm{ED}}$, ratio of potassium concentration in tubule fluid at early distal site/perfusion fluid; $\mathbf{J}_{\mathbf{K}}$, absolute reabsorption of potassium; $\mathbf{F R}_{\mathbf{K}}$, fractional reabsorption of potassium entering loop of Henle. Number of tubules in parentheses. Data represent mean \pm SE.

* $P<0.05$ vs. control and ALDO.

$\ddagger P<0.01$ vs. control and ALDO.

Ultrastructural data: loop of Henle. Results of the morphometric analysis are presented in Table VI. Adrenalectomy and adrenal corticosteroid replacement were without a detectable effect on cell structure. There was no statistically significant change in either the surface density or boundary length of the luminal or basolateral cell membrane, in the cortical or medullary thick ascending limb portions of the loops of Henle, after ADX or hormone treatment. Furthermore, neither cell area nor the volume density of mitochondria were affected by ADX or hormone treatment.

Transport data: distal tubule. Results are summarized in Table VII and Figs. 3 and 4. In this series of experiments the flow rate of fluid entering the distal tubule was similar in all groups. Net water reabsorption, by the distal tubule, was also similar in all groups.

As illustrated in Fig. 3, ADX dramatically inhibited sodium reabsorption from $378.0 \pm 31.0$ to $211.7 \pm 19.9 \mathrm{pmol} / \mathrm{min}$. Both aldosterone and dexamethasone significantly increased sodium transport in adrenalectomized animals; however, only aldosterone increased reabsorption to control values.

ADX and adrenal corticosteroids also had a significant effect on potassium transport (Fig. 4 and Table VII). Potassium was secreted at a rate of $61.5 \pm 8.2 \mathrm{pmol} / \mathrm{min}$ in control. Adrenalectomy reduced secretion to $40.3 \pm 5.9 \mathrm{pmol} / \mathrm{min}$. Whereas dexamethasone replacement had no significant effect on potassium secretion, compared with adrenalectomy alone, aldosterone stimulated secretion to $63.2 \pm 7.2 \mathrm{pmol} / \mathrm{min}$, a value that was similar to the control rate of $61.5 \pm 8.2 \mathrm{pmol} / \mathrm{min}$.

The concentration of potassium in fluid entering the early distal tubule was altered by ADX and hormone replacement. In both $\mathrm{ADX}$ and DEX, the concentration of potassium in early distal tubule fluid was significantly higher than in control and ALDO. However, the ratios of potassium in tubule fluid/plasma

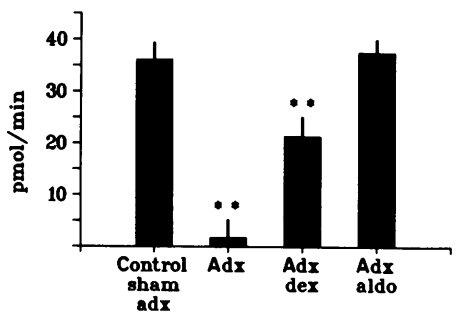

Figure 2. Potassium reabsorption: loop of Henle. ${ }^{* *} P<0.01$ vs. controlsham and ADX-ALDO. ADX-DEX is also significantly greater than ADX ( $P$ $<0.01)$. Data represent mean $\pm \mathrm{SE}$. 


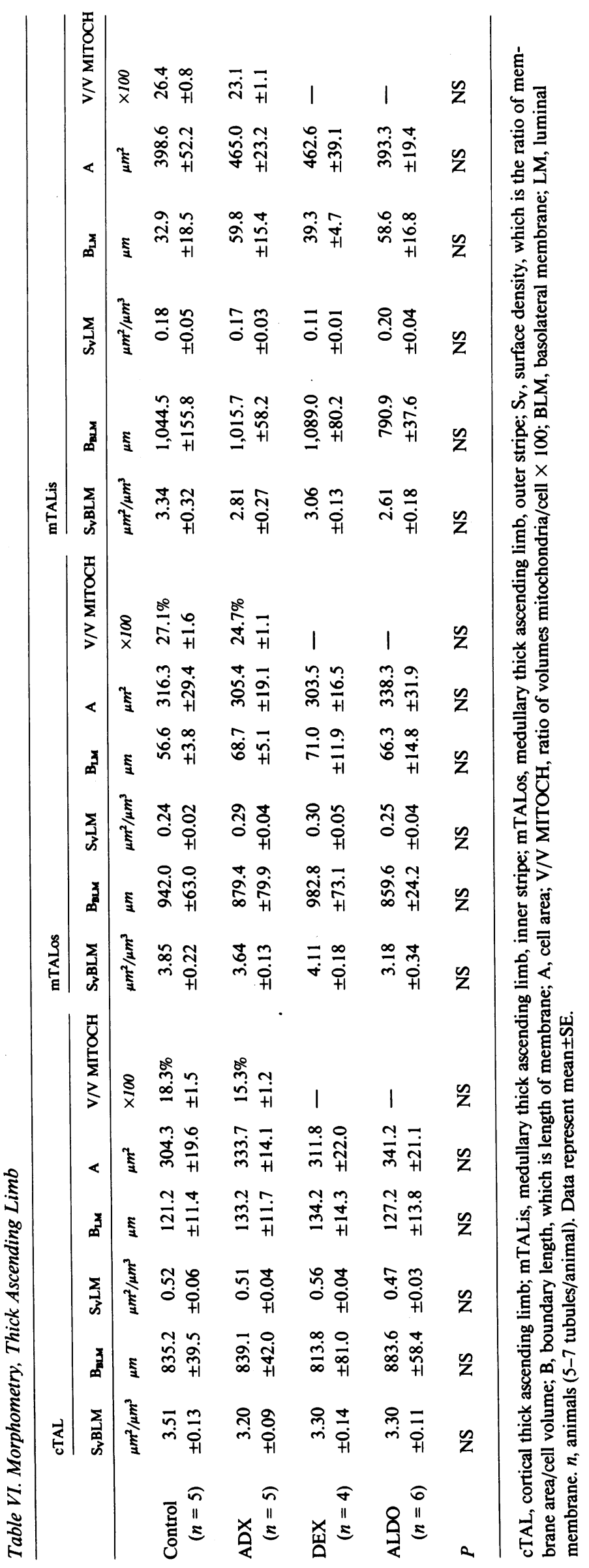


Table VII. Sodium Reabsorption and Potassium Secretion: Distal Tubule

\begin{tabular}{|c|c|c|c|c|c|c|c|c|c|c|c|c|c|}
\hline & $V_{E D}$ & $\mathbf{J}_{\mathbf{v}}$ & {$[\mathrm{Na}]_{\text {ED }}$} & {$[\mathrm{Na}]_{\mathbf{L D}}$} & $\mathrm{TF} / \mathrm{P}_{\mathrm{N}_{\mathrm{a}}} \mathrm{ED}$ & $\mathrm{TF} / \mathrm{P}_{\mathrm{Na}} \mathrm{LD}$ & $\mathrm{J}_{\mathrm{Na}}$ & {$[\mathrm{K}]_{\mathrm{ED}}$} & {$[\mathrm{K}]_{L \mathbf{D}}$} & $\mathrm{TF} / \mathrm{P}_{\mathbf{k}} \mathrm{ED}$ & $\mathrm{TF} / \mathrm{P}_{\mathbf{K}} \mathrm{LD}$ & $\mathbf{J}_{\mathbf{K}}$ & $\begin{array}{l}\text { K delivery, } \\
\text { late distal } \\
\text { tubule }\end{array}$ \\
\hline & $n l / \min$ & $\mathrm{nl} / \mathrm{min}$ & $m M$ & $m M$ & & & $\mathrm{pmol} / \mathrm{min}$ & $m M$ & & & & $\mathrm{pmol} / \mathrm{min}$ & $\mathrm{pmol} / \mathrm{min}$ \\
\hline Control & 13.90 & 2.74 & 87.8 & 76.4 & 0.62 & 0.53 & $378.0^{*}$ & 3.15 & 9.07 & 0.73 & $2.09^{\prime \prime}$ & $-61.5^{\prime \prime}$ & 102.5 \\
\hline$(n=8)$ & \pm 1.05 & \pm 0.99 & \pm 5.4 & \pm 4.8 & \pm 0.04 & \pm 0.04 & \pm 31.0 & \pm 0.28 & \pm 1.12 & \pm 0.06 & \pm 0.22 & \pm 8.2 & \pm 9.1 \\
\hline ADX & 13.83 & 2.19 & 84.4 & 81.2 & 0.58 & 0.56 & $211.7 \ddagger$ & 4.79 & 8.66 & 0.78 & $1.44 \ddagger$ & $-40.3 \ddagger$ & 103.6 \\
\hline$(n=6)$ & \pm 0.47 & \pm 0.29 & \pm 5.7 & \pm 5.9 & \pm 0.04 & \pm 0.04 & \pm 19.9 & \pm 0.70 & \pm 0.75 & \pm 0.09 & \pm 0.10 & \pm 5.9 & \pm 11.7 \\
\hline DEX & 14.30 & 3.43 & 89.2 & 87.9 & 0.63 & 0.62 & $326.2^{*}$ & $4.63 \ddagger$ & 8.67 & 0.70 & $1.31 \ddagger$ & $-29.8 \ddagger$ & 95.3 \\
\hline$(n=8)$ & \pm 0.53 & \pm 0.40 & \pm 4.3 & \pm 4.1 & \pm 0.03 & \pm 0.03 & \pm 36.3 & \pm 0.27 & \pm 0.80 & \pm 0.04 & \pm 0.09 & \pm 7.7 & \pm 6.5 \\
\hline ALDO & 15.57 & 4.33 & 88.2 & 80.6 & 0.62 & 0.59 & $457.6^{*} \S$ & $3.03^{\prime \prime}$ & 8.57 & 0.61 & $1.76^{\prime \prime}$ & $-63.2^{\mathrm{H}}$ & 107.3 \\
\hline$(n=7)$ & \pm 0.52 & \pm 0.51 & \pm 4.5 & \pm 5.9 & \pm 0.05 & \pm 0.05 & \pm 56.0 & \pm 0.15 & \pm 0.51 & \pm 0.15 & \pm 0.11 & \pm 7.2 & \pm 7.4 \\
\hline$P$ & NS & NS & NS & NS & NS & NS & S & S & NS & NS & S & $S$ & NS \\
\hline
\end{tabular}

$\mathrm{V}_{\mathrm{ED}}$, flow rate, early distal tubule; $\mathrm{J}_{\mathrm{V}}$, water reabsorption; $\mathrm{ED}$, early distal tubule; $\mathrm{LD}$, late distal tubule; $T F / P$, tubule fluid/plasma concentration ratio; $J_{\mathrm{Na}}$, sodium reabsorption; $\mathrm{J}_{\mathrm{K}}$, potassium secretion. $n$, number of tubules where fluid was collected from both early and late distal segments. $\mathrm{S}$, significant differences among groups where ${ }^{*} P<0.01$ vs ADX; $\ddagger P<0.01$ vs. control; $\S P<0.05$ vs DEX; and $P<0.01$ vs. ADX and DEX. Data represent mean \pm SE.

in the early distal tubule were similar in all experimental groups. Potassium concentration in late distal tubule fluid was similar in all groups, ranging between 8.57 and $9.07 \mathrm{mM}$. Because plasma potassium increased in ADX and DEX, the ratios of potassium in tubule fluid/plasma decreased in these two groups compared with control and ALDO. Accordingly, net potassium secretion by the distal tubule was significantly reduced in ADX and DEX animals (Fig. 4).

Although potassium secretion was reduced along the distal tubule in ADX and DEX, the rate of potassium delivery to the end of the late distal tubule was similar in all groups (Table VII). This resulted from a decrease in the rate of potassium reabsorption in the loop of Henle, which offset the reduction in potassium secretion by the distal tubule.

\section{Discussion}

The purpose of this study was to examine the regulation of sodium and potassium transport by the loop of Henle and distal tubule by physiological levels of mineralocorticoids and glucocorticoids. One of the main conclusions of this study is that chronic alterations in mineralocorticoid levels regulates sodium reabsorption in the thick ascending limb of Henle's loop. Thus, it is reasonable to conclude that the defect in the ability to concentrate the urine maximally during adrenal insufficiency results in part from a reduction in the aldosterone-dependent singleeffect of the counter current multiplier.

Potassium reabsorption in the loop of Henle is also regulated by adrenal corticosteroids. Both classes of hormone stimulated

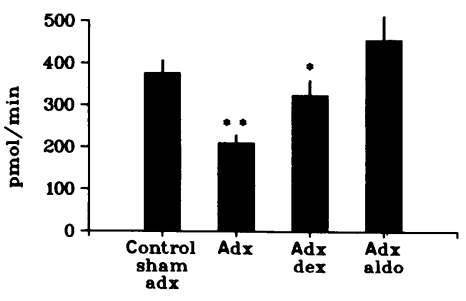

Figure 3. Sodium reabsorption: distal tubule. ${ }^{*} P$ $<0.05$ vs. ADX. ${ }^{* *} P$ $<0.01$ vs. control-sham and ADX-ALDO. Data represent mean $\pm \mathrm{SE}$. potassium reabsorption in adrenalectomized animals, although only aldosterone restored reabsorption to normal.

In addition, the present study also demonstrates that alterations in mineralocorticoid hormones within the physiological range controls sodium reabsorption and potassium secretion in the distal tubule.

Sodium transport: loop of Henle. Several previous studies have also shown that sodium reabsorption in the loop of Henle is reduced by adrenalectomy, thereby increasing sodium concentration in early distal tubule fluid (4-7). Inasmuch as sodium reabsorption by the thick ascending limb of Henle's loop reduces sodium concentration in tubule fluid, due to the low osmotic water permeability of this segment (14), it is concluded that the reduction of sodium transport in the loop of Henle, after adrenalectomy, occurs in part in the thick ascending limb. This conclusion is supported by the recent observations of Work and Jamison (30), who found that adrenalectomy reduced sodium reabsorption by isolated and perfused rat medullary thick ascending limbs and that chronic aldosterone replacement $(0.5$ $\mu \mathrm{g} / 100 \mathrm{~g}$ per day) increased reabsorption to normal rates.

The effects of hormone replacement on sodium transport in the loop of Henle in adrenalectomized rats have also been examined previously. When tubule flow rate was held constant by microperfusion, Murayama et al. (7) found that large acute doses of cortisol did not have a significant effect on solute reabsorption in the loop of Henle. In contrast, in a more recent microperfusion study, dexamethasone increased sodium reabsorption in the loop of Henle; however, the physiological significance of this effect is questionable because a large dose $(50 \mu \mathrm{g} / 100 \mathrm{~g}$ per d) of the

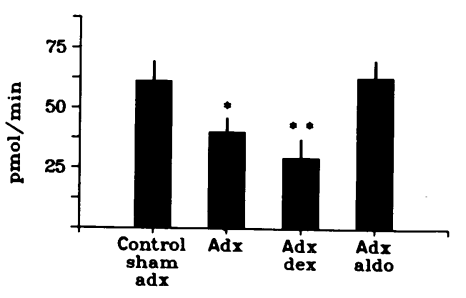

Figure 4. Potassium secretion: distal tubule. ${ }^{*} P$ $<0.05$ and ${ }^{* *} P<0.01$ vs. control-sham and ADXALDO. Data represent mean \pm SE 
steroid was given chronically to adrenalectomized rats (5). Under these conditions, with high plasma dexamethasone levels, the hormone binds to both mineralocorticoid and glucocorticoid receptors (11). Accordingly, it is not certain whether dexamethasone stimulated transport through binding to the glucocorticoid or mineralocorticoid receptor.

In a recent free-flow micropuncture study, in adrenalectomized rats, dexamethasone increased sodium reabsorption in the loop of Henle (8). However, glucocorticoids increase glomerular filtration rate $(12,20)$ and hence the rate of fluid and sodium delivery to the loop of Henle, an effect that could have enhanced sodium reabsorption in the loop of Henle independent of adrenal corticosteroids $(15,16)$.

In a previous study we found that the dose of dexamethasone used in the present study produced a plasma dexamethasone level of $20.7 \mathrm{nM}(20)$, a value that is $2-4$ times higher than the dissociation constant of the renal glucocorticoid receptor (5-10 $\mathrm{nM} ; 11,20,22)$. In that study we also found that dexamethasone increased glomerular filtration rate in ADX animals to levels observed in adrenal-intact rats (20). Thus, our inability to demonstrate a significant effect of dexamethasone on sodium reabsorption cannot be ascribed to an insufficient plasma level.

A few studies have examined the effects of aldosterone on sodium reabsorption by the loop of Henle, using free-flow micropuncture techniques. In these studies aldosterone was without effect $(4,6)$. One possible explanation for these findings is that adrenalectomy and hormone replacement produce alterations in glomerular filtration rate, tubule flow rate, and changes in the composition of tubule fluid entering the loop of Henle (48). As stated above, these factors influence sodium reabsorption by the loop of Henle $(19,21)$. Thus, alterations in these variables among experimental groups could obscure a direct, stimulatory effect of aldosterone on transport. In the present study, these factors were held constant by microperfusion, and aldosterone augmented sodium reabsorption in the thick ascending limb.

Four lines of evidence are consistent with the conclusion that aldosterone controls sodium reabsorption in the thick ascending limb. First, as discussed above, Work and Jamison (30) report that adrenalectomy reduces sodium reabsorption in the medullary thick ascending limb of rat and chronic aldosterone treatment restores transport to normal. Second, Farman and coworkers $(31,32)$ found a modest level of aldosterone-specific binding sites in the thick ascending limb in rat kidney. Third, Green, Harrington, and Valtin (33) have demonstrated that adrenalectomy reduces the generation of free water and that aldosterone, but not prednisolone, increased free water clearance. Finally, aldosterone administration to adrenalectomized animals increases the ability to concentrate maximally the urine, an action consistent with an effect on the thick ascending limb of Henle $(1-3,7)$.

The results from biochemical studies on the thick ascending limb are also relevant. Adrenalectomy reduces the activity of $\mathrm{Na}, \mathrm{K}-\mathrm{ATPase}$ in both the cortical and medullary segments of the thick ascending limb (34-41). Although early studies indicated that aldosterone was capable of increasing the activity of $\mathrm{Na}, \mathrm{K}-\mathrm{ATP}$ Tase after adrenalectomy $(36,39,40)$, more recent studies have shown that dexamethasone but not aldosterone increases enzyme activity $(34,35,38)$. The reason why we were unable to detect a significant effect of dexamethasone on sodium transport, while similar hormone levels have been shown to increase the activity of $\mathrm{Na}, \mathrm{K}-\mathrm{ATPase}$ in the thick ascending limb $(35,36)$, is not known. Additional transport studies on isolated thick ascending limbs must be conducted to answer this question directly.

Potassium transport: loop of Henle. The effect of adrenal corticosteroids on the rate of potassium transport by the loop of Henle has received little attention. Cortney (4) and Hierholzer et al. (6) concluded from free-flow micropuncture studies that adrenalectomy reduced potassium reabsorption in the superficial loop of Henle. Higashihara and Kokko (9) and Hierholzer et al. (6) did not observe an effect of an aute infusion of aldosterone on potassium reabsorption in the loop of Henle. This latter observation contrasts with the results in the present study, in which chronic aldosterone treatment stimulated potassium reabsorption. The different conclusions may be related to the techniques used in these studies and to the length of exposure to the hormone. In the present study the initial flow rate and composition of fluid entering the loop of Henle were similar among all groups, whereas small differences in flow rate and the composition of tubule fluid were present between groups in the two aforementioned studies $(6,9)$. Because flow rate is an important determinant of potassium as well as sodium transport in the loop of Henle, even small differences in these variables between experimental groups could obscure an effect of the hormone on transport (16-18).

Ultrastructure: loop of Henle. Adrenalectomy had no apparent effect on the ultrastructure of the loop of Henle when examined both qualitatively and by morphometric analysis. Cell structure in the control state was similar to that reported by Kone et al. (29).

In contrast to the lack of effect of adrenalectomy on the thick ascending limb, in a previous study we found that adrenalectomy sharply reduced the area of the basolateral membrane of principal cells in the initial collecting tubule (late distal tubule) of rat (42). This change in cell structure correlated with a decline in the activity of $\mathrm{Na}, \mathrm{K}-\mathrm{ATPase}(35)$ and with a defect in the ability to reabsorb sodium and secrete potassium $(20,23)$. Thus, the lack of a significant change in cell structure after adrenalectomy indicates that either adrenal hormones do not influence cell structure in this segment or that the effect of adrenalectomy was too small to be detected by morphometric analysis.

Sodium transport: distal tubule. Sodium reabsorption by the distal tubule was sharply inhibited by adrenalectomy and was restored to control values by aldosterone. This observation confirms previous studies $(4,6,10,19)$ and extends these investigations by demonstrating a direct stimulatory effect of physiological levels of aldosterone on sodium reabsorption.

Chronic, physiologic dexamethasone replacement also increased sodium reabsorption by the distal tubule, although the effect was less than that produced by aldosterone and the steroid did not restore transport to normal. In contrast, Wiederholt et al. (43), Field et al. (24), and Wingo et al. (44) have shown that acute exposure to dexamethasone was without effect on sodium reabsorption by the distal or cortical collecting tubule. The reason for these disparate observations are not presently known.

Potassium transport: distal tubule. This study also demonstrates that chronic alterations in plasma aldosterone regulate potassium secretion by the superficial distal tubule. We have shown previously that "acute" increases in aldosterone levels within the physiological range stimulate potassium secretion by the distal tubule of rat (24). Numerous studies have also shown that pharmacological doses of aldosterone enhance potassium secretion by the distal and cortical collecting tubule (references 6,9 , and 10, and reviewed in references 19, 21, and 22). Although 
it is commonly recognized that mineralocorticoids regulate potassium secretion by these nephron segments, an effect of longterm changes in physiological levels has not been demonstrated previously.

The distal tubule of the rat is a heterogeneous epithelium, and is composed of three segments: distal convoluted, connecting, and initial collecting (27). Previous studies have demonstrated that sodium reabsorption and potassium secretion by the connecting and initial collecting tubule are stimulated by potassium adaptation, which increases plasma aldosterone (27). Thus, it is likely that in the present study, aldosterone increased sodium and potassium transport in these segments of the distal tubule. Little is known about the function of the distal convoluted tubule: however, the available data suggest that aldosterone is without effect on sodium and potassium transport by this segment $(19,21,27,45)$.

\section{Conclusions}

This study demonstrates that physiological levels of aldosterone regulate sodium reabsorption in the loop of Henle. In addition, the data suggest that the defect in the ability to concentrate the urine in adrenal-insufficient animals is due in part to a reduction in the aldosterone-dependent single effect of countercurrent multiplication. Both classes of adrenal corticosteroids stimulate potassium reabsorption in the loop of Henle. Finally, physiological levels of aldosterone regulate sodium reabsorption and potassium secretion by the distal tubule.

\section{Acknowledgments}

I thank Dr. Heinz Valtin for his advice and generous support during these experiments and for his suggestions on the manuscript. Dr. Gerhard Giebisch, Dr. David Good, and Dr. David Young provided valuable discussions and advice during the preparation of the manuscript. I also thank Ellen Puglisi for able technical assistance.

This work was supported by research grant AM 34533 from the U. S. Public Health Service, the Hitchcock Foundation, and by BRSG funds from Dartmouth Medical School, Hanover, NH. Dr. Stanton is an Established Investigator of the American Heart Association.

\section{References}

1. Cooke, C. R., and R. W. Steenburg. 1973. Effects of aldosterone and cortisol on the renal concentrating mechanism. J. Lab. Clin. Invest. 82:784-792.

2. Schwartz, M. J., and J. P. Kokko. 1980. Urinary concentrating defect of adrenal insufficiency: permissive role of adrenal steroid on the hydroosmotic response across the rabbit cortical collecting tubule. $J$. Clin. Invest. 66:234-242.

3. Sigler, M. H., J. N. Forrest, Jr., and J. R. Elkinton. 1965. Renal concentrating ability in the adrenalectomized rat. Clin. Sci. 28:29-37.

4. Cortney, M. A. 1969. Renal tubular transfer of water and electrolytes in adrenalectomized rats. Am. J. Physiol. 216:580-598.

5. Gutsche, H.-U., R. Muller-Suur, K. F. Samwer, G. Beer, and K. Hierholzer. 1980. Tubuloglomerular feedback control in kidneys of adrenalectomized rats. Pfluegers Arch. 386:11-19.

6. Hierholzer, K., M. Wiederholt, H. Holzgreve, G. Giebisch, R. M. Klose, and E. E. Windhager. 1965. Micropuncture study of renal transtubular concentration gradients of sodium and potassium in adrenalectomized rats. Pfluegers Arch. 285:193-210.

7. Murayama, Y., A. Suzuki, M. Tadokoro, and F. Sakai. 1968. Microperfusion of Henles loop in the kidney of the adrenalectomized rat. Jap. J. Pharm. 18:518-519.

8. Welch, W. J., C. E. Ott, G. P. Guthrie, Jr., and T. A. Kotchen.
1985. Renin secretion and loop of Henle chloride reabsorption in the adrenalectomized rat. Am. J. Physiol. 249:F596-F602.

9. Higashihara, E., and J. P. Kokko. 1985. Effects of aldosterone on potassium recycling in the kidney of adrenalectomized rats. Am. J. Physiol. 248:F219-F227.

10. Wiederholt, M., C. Behn, W. Schoormans, and L. Hansen. 1972. Effect of aldosterone on sodium and potassium transport in the kidney. J. Steroid Biochem. 3:151-159.

11. Edelman, I. S. 1981. Receptors and effectors in hormone action on the kidney. Am. J. Physiol. 241:F333-F339.

12. Baylis, C., and B. M. Brenner. 1978. Mechanism of the glucocorticoid-induced increase in gomerular filtration rate. Am. J. Physiol. 234:F166-F170.

13. Berliner, R. W., and D. G. Davidson. 1957. Production of hypertonic urine in the absence of pituitary antidiuretic hormone. J. Clin. Invest. 36:1416-1427.

14. Hebert, S. C., and T. E. Andreoli. 1984. Control of $\mathrm{NaCl}$ transport in the thick ascending limb. Am. J. Physiol. 246:F745-F756.

15. Landwehr, D. M., J. Schnermann, R. M. Klose, and G. Giebisch. 1968. Effect of reduction in filtration rate on renal tubular sodium and water reabsorption. Am. J. Physiol. 215:687-695.

16. Levine, D. Z., R. A. McLeod, and M. K. Byers. 1978. Flow correlation of loop of Henle potassium influx. Can. J. Physiol. Pharm. 56:533-535.

17. Morgan, T., and R. W. Berliner. 1969. A study by microperfusion of water and electrolyte movements in the loop of Henle and distal tubule of the rat. Nephron. 6:388-405.

18. Schnermann, J. 1968. Microperfusion study of single short loops of Henle in rat kidney. Pfluegers Arch. 300:255-282.

19. Stanton, B., and G. Giebisch. 1981. Mechanism of urinary potassium excretion. Miner. Electrolyte Metab. 5:100-120.

20. Stanton, B., G. Klein-Robbenhaar, J. Wade, G. Giebisch, and R. DeFronzo. 1985. Effects of adrenalectomy and chronic adrenal corticosteroid replacement on potassium transport in rat kidney. J. Clin. Invest. 75:1317-1326.

21. Wright, F. S., and G. Giebisch. 1978. Renal potassium transport: contribution of individual nephron segments and populations. Am. J. Physiol. 235:F515-F527.

22. Marver, D. 1984. Evidence of corticosteroid action along the nephron. Am. J. Physiol. 246:F111-F123.

23. Wingo, C. S. 1984. Effect of ouabain on K secretion in cortical collecting tubules from adrenalectomized rabbits. Am. J. Physiol. 247: F588-F595.

24. Field, M. J., B. A. Stanton, and G. H. Giebisch. 1984. Differential acute effects of aldosterone, dexamethasone and hyperkalemia on distal tubular potassium secretion in the rat kidney. J. Clin. Invest. 74:17921802.

25. Pert, W. S., and A. C. Pessina. 1975. The mechanism of acute renal ischemia caused by adrenalectomy in the rat. J. Physiol. (Lond.). 250:23-37.

26. Schafer, J. A., S. L. Troutman, and T. E. Andreoli. 1974. Volume reabsorption, transepithelial potential differences and ionic permeability properties in mammalian superficial proximal straight tubules. J. Gen. Physiol. 64:582-607.

27. Stanton, B. A., D. Biemesderfer, J. B. Wade, and G. Giebisch. 1981. Structural and functional study of the rat distal nephron: effects of potassium adaptation and depletion. Kidney Int. 19:36-48.

28. Rastegar, A., D. Biemesderfer, M. Kashgarian, and J. Hayslett. 1980. Changes in membrane surfaces of collecting duct cells in potassium adaptation. Kidney Int. 18:293-301.

29. Kone, B. C., K. M. Madsen, and C. C. Tisher. 1984. Ultrastructure of the thick ascending limb of Henle in the rat kidney. Am. J. Anatomy 171:217-226.

30. Work, J., and R. Jamison. 1986. Effect of adrenalectomy on transport in the rat medullary thick ascending limb. Proc. Int. Union Physiol. Sci., Vol. 16. 285A.

31. Farman, N., A. Vandewalle, and J. P. Bonvalet. 1982. Binding sites of mineralo and glucocorticoids along the mammalian nephron (rat 
and rabbit). In: Biochemistry of Kidney Functions, Symposium No. 21, ed. F. Morel. Elsevier Biomedical Press. 285-291.

32. Farman, N., and J. P. Bonvalet. 1983. Aldosterone binding in isolated tubules. III Autoradiography along the rat nephron. Am. J. Physiol. 245:F606-F614.

33. Green, H. H., A. R. Harrington, and H. Valtin. 1970. On the role of antidiuretic hormone in the inhibition of acute water diuresis in adrenal insufficiency and the effects of gluco- and mineralocorticoids in reversing the inhibition. J. Clin. Invest. 49:1724-1736.

34. El Mernissi, G., and A. Doucet. 1983. Short term effect of aldosterone on renal sodium transport and tubular Na-K-ATPase in the rat. Pfluegers Arch. 399:139-146.

35. Garg, L. C., N. Narang, and C. S. Wingo. 1985. Glucocorticoid effects on Na-K-ATPase in the rabbit nephron segments. Am. J. Physiol. 248:F487-F491.

36. Horster, M., H. Schmidt, and U. Schmidt. 1980. Aldosterone in vitro restores nephron Na-K-ATPase of distal segments from adrenalectomized rabbits. Pfluegers Arch. 384:203-206.

37. Mujais, S. K., M. A. Chekal, W. J. Jones, J. P. Hayslett, and A. I. Katz. 1985. Modulation of renal sodium-potassium-adenosine triphosphatase by aldosterone: effect of high physiologic levels on enzyme activity in isolated rat and rabbit tubules. J. Clin. Invest. 76:170-176.

38. Rayson, B. M., and S. O. Lowther. 1984. Steroid regulation of
$\mathrm{Na}^{+}-\mathrm{K}^{+}$ATPase: differential sensitivities along the nephron. Am. J. Physiol. 246:F656-F667.

39. Schmidt, U., and U. C. Dubach. 1970. The behavior of $\mathrm{Na}^{+}, \mathrm{K}^{+}$. activated adenosine triphosphatase in various structures of the rat nephron after furosemide application. Nephron. 7:447-458.

40. Schmidt, U., J. Schmid, H. Schmid, and U. C. Dubach. 1975. Sodium and potassium activated ATPase: a possible target of aldosterone. J. Clin. Invest. 55:655-660.

41. Marver, D., and W. E. Lombard. 1981. Localization of aldosterone-target sites in rabbit renal medulla. Kidney Int. 19:248A. (Abstr.)

42. Stanton, B., A. Janzen, J. Wade, R. DeFronzo, and G. Giebisch. 1985. Ultrastructure of rat initial collecting tubule: effect of adrenal corticosteroid treatment. J. Clin. Invest. 75:1317-1326.

43. Wiederholt, M., and B. Wiederholt. 1968. Der Einflus von Dexamethason auf die Wasser-und Electrolyt-ausscheidung adrenalektomierter Ratten. Pfluegers Arch. 302:57-78.

44. Wingo, C. S., J. P. Kokko, and H. R. Jacobson. 1985. Effects of in vitro aldosterone on the rabbit cortical collecting tubule. Kidney Int. 28:51-57.

45. Gross, J. B., and J. P. Kokko. 1977. Effects of aldosterone and potassium sparing diuretics on electrical potential differences across distal nephron. J. Clin. Invest. 59:82-89. 